ALPHA N² 28 Julio 2009 (9-27)

ISSN 0716-4254

http://alpha.ulagos.cl

\title{
LA CUESTIÓN DE LA IDENTIDAD NACIONAL EN LAS NOTAS DE ARTE Y MILTÍN 1934, DE JUAN EMAR
}

The question of national identity in Notas de Arte and Miltín 1934, by Juan

Emar

Ignacio Álvarez*

Hay veces que es mejor ser antipatriota.

Notas de Arte

Todo el mundo en Chile es chileno; es algo desesperante.

Miltín 1934

Resumen

La vanguardia literaria aporta aires cosmopolitas al campo cultural latinoamericano, pero en muchos escritores existe una aguda preocupación nacional bien coordinada con los horizontes mundiales. Este artículo muestra cómo Juan Emar, autor cosmopolita, interviene en el debate sobre el arte nacional en Chile durante los años veinte y treinta: si hay una identidad nacional en la actividad artística, propone en sus Notas de Arte, ella aparece en la representación como proceso y no en sus meros objetos. La novela Miltín 1934 (1935) pondrá en juego este precepto mostrando la caducidad del pacto nacional decimonónico y la renuencia de su autor a formar parte de una nueva nacionalidad, colectiva y popular, que se construirá a lo largo del siglo XX.

Palabras clave: Nación, vanguardia literaria, Juan Emar, narrativa chilena.

\begin{abstract}
The literary avant-garde represents a cosmopolitan trend in Latin America, but in many writers there is also an important concern about national identity. This article shows how Juan Emar, a cosmopolitan Chilean author, takes part in the discussion about national art during the 1920's and 1930's. If artistic activity carries a national identity, he proposes, in his Notas de Arte, it appears in representation as a process, not as an object. The novel Miltín 1934 (1935) will put into practice this rule by showing the lapse of 19th century national pact and the author's reluctance to commit to a new nationality, collective and popular, that will be constructed throughout the 20th century.
\end{abstract}

Key words: Nation, literary avant-garde, Juan Emar, Chilean narrative. 


\section{Ignacio Álvarez}

No resulta posible, entrados ya en el siglo XXI, soslayar la obra artística y cultural que Juan Emar desarrolló en las primeras décadas del siglo pasado. Tampoco, como ocurriera por décadas, es Emar ese ilustre desconocido cuya lectura fuera "privilegio de ciertas cofradías subterráneas que parecieran guardar celosamente un secreto que nadie les disputa” (Piña et al. 1990:7). Desde hace por lo menos quince años las ediciones de sus escritos y los estudios académicos han aumentado de manera sostenida, a tal punto que nadie discute ya su inclusión en la corriente central de la narrativa chilena del siglo XX ni pone en entredicho ciertos juicios laudatorios que en su momento parecieron osados o exagerados. ${ }^{1}$

Ha terminado el rescate, ${ }^{2}$ entonces, y es hora de hacer dialogar esos textos con problemas más generales; con otras obras ya canonizadas, por ejemplo, o con los debates que acucian el contexto cultural de su escritura. Esto último es, precisamente, lo que intentaré en este trabajo, que explora la encrucijada que forman las Notas de Arte, ${ }^{3}$ la novela Miltín 1934 (1935) y las tribulaciones de la identidad nacional en el Chile de las décadas del veinte y del treinta. ${ }^{4}$ Emar, propongo, interviene activamente en el debate sobre el arte chileno, y lo hace de una forma que sorprende por la consistencia con su pensamiento estético global. Si hay una identidad nacional en el arte, sugiere en las Notas, ella aparece en la representación artística como proceso y no en sus meros objetos. En la escritura de Miltín 1934, unos años más tarde, pondrá

\footnotetext{
1 “Es el pilar de una historia de la literatura que está por escribirse” (Piña et al. 1990:7); "habría cambiado el curso del modo de contar de los chilenos" (Huneeus, 2001:54); “el único narrador chileno de este siglo que merece figurar entre sus poetas... para quien, más allá del "talento”, la adjudicación de cierto "genio" no es un disparate" (Valente, 1972:7).

${ }^{2}$ Paula Peña, a quien sigo en este punto, ha ordenado la recepción de la obra de Juan Emar en tres períodos: silencio (desde su aparición hasta la década del ochenta), rescate (de los ochenta al dos mil) y canonización, el momento actual (2008:5-8).

3 Jean Emar. Notas de Arte (Juan Emar en La Nación, 1923-1927). Estudio y recopilación de Patricio Lizama. Santiago: RIL/Centro de Investigaciones Diego Barros Arana, 2003. El corpus comprende una serie de artículos escritos para la sección del mismo nombre del diario. Citaremos por esta edición.

${ }^{4}$ En concordancia con B. Anderson (2000:22-5), E. Hobsbawm (1990:9-21) y la mayor parte de quienes se ocupan seriamente del asunto, este trabajo considera la nación como un constructo cultural y no como una realidad natural. Grínor Rojo la concibe, a su vez, como una vertiente moderna de la identidad particular. Rojo argumenta convincentemente el carácter identitario de lo nacional y su lugar en la categoría hegeliana y lukacsiana de lo particular (2006:49). A diferencia de E. Gellner (1991:13) y Hobsbawm (2000:175), y siguiendo nuevamente a Rojo, la idea de nación se presenta precediendo "si es que no cronológica en cualquier caso éticamente al ordenamiento (y por tanto a la división) de la sociedad en instituciones y grupos económicos diversos” (Rojo et al. 2003:35), de modo que el orden de lo nacional es anterior al estatal y anterior, también, al uso ideológico que se haga de él.
} 
en juego ese precepto exhibiendo la caducidad del pacto nacional decimonónico y su propia renuencia a integrarse a la nueva nacionalidad, colectiva y popular, que se construye a lo largo del siglo XX.

CHILE Y LA COSMÓPOLIS: ELABORACIÓN TEÓRICA DE LO NACIONAL EN LAS NOTAS DE ARTE

La actividad de las vanguardias revivió con fuerza el secular debate latinoamericano que opone las tendencias encontradas del nacionalismo y el cosmopolitismo. Durante el siglo XIX ese debate había sido sostenido casi exclusivamente por las elites criollas y pretendía resolverse mediante una virtual "invención de la nación" a partir de los habitantes de un paisaje supuestamente virgen, reemplazando eso sí la fuente cultural hispánica por la francesa libertaria. ${ }^{5}$ El Centenario de la Independencia pone, otra vez, el tema nacional en el tapete $\mathrm{y}$, al menos en el caso de Chile, un hondo descontento atraviesa el ánimo de personas e instituciones. El malestar se manifiesta no sólo como decadencia moral o política sentida desde dentro de la oligarquía (el caso de Enrique Mac-Iver o de Francisco Antonio Encina) sino que involucra, también, a los sectores sociales que pujan por integrarse a la vida nacional, como se lee en los ensayos de Alejandro Venegas, Nicolás Palacios y, sobre todo, en Luis Emilio Recabarren. ${ }^{6}$ De modo global, las primeras décadas del siglo enfrentan una crisis de legitimidad y de predominio político de las elites dirigentes (Salazar y Pinto 1999:40) cuya manifestación, tal vez contrafóbica, es el surgimiento de prácticas culturales de un cuño nacionalista a veces estrecho. El nacionalismo, señala Bernardo Subercaseaux, es "la fuerza cultural dominante del período”, y el espíritu de vanguardia (con el que identificamos a Emar) constituiría la discursividad modernizadora que se le opone (2004:13).

Las obras de vanguardia, es cierto, aportan aires cosmopolitas a las literaturas latinoamericanas y Jorge Schwartz ha identificado esta apertura de las fronteras culturales no sólo como pura referencia, sino en términos de una

\footnotetext{
${ }^{5}$ La mejor ilustración de la voluntad nacionalista decimonónica en Chile sigue siendo el “Discurso inaugural de la Sociedad Literaria”, que José Victorino Lastarria leyó en 1848.

${ }^{6}$ Me refiero a tres textos fundamentales para el período: Sinceridad. Chile íntimo en 1910 (1910) de Alejandro Venegas, firmado con el pseudónimo de Julio Valdés Cange; Raza chilena (1904) de Nicolás Palacios, y Ricos y pobres a través de un siglo de vida republicana (1910) de Luis Emilio Recabarren. El excelente volumen El Chile del centenario. Los ensayistas de la crisis, editado por Cristián Gazmuri en 2001, es una antología que contextualiza esta discusión y que incluye, entre otros, el texto de Recabarren y algunos ensayos breves de Venegas y Palacios.
} 
Ignacio Álvarez

práctica textual. El "texto cosmópolis” de la vanguardia no sólo describe su referente internacional, sino que lo reconstruye en la escritura de manera fragmentaria, indicial y metonímica (1983:18-23). En Miltín 1934, a mi juicio, es posible hablar de un cosmopolitismo textual parecido al que describe Schwartz y que va más allá de las obvias referencias metaliterarias o pictóricas. El conflicto entre Emar, Gilberto Moya y Sandalio Tal, por ejemplo, en el que se discute acerca de la alienación ideológica bajo la figura inexorable del péndulo, gira temáticamente, sin embargo, en torno al largo y célebre juicio a Henri Desiré Landru, sin entregar a los lectores que no vivimos en Francia la más mínima información que sirva para comprenderlo (56-59). ${ }^{7}$ En la misma línea se sitúa, y de un modo más evidente, la alusión a Bertoldt Brecht que leemos en el capítulo La tournée des Grands Ducs (1728)

Una canción entusiasta que hemos oído recientemente en La ópera de 4 centavos, dice:

Les canons tonnent, Nos pas résonnent...

Así marchábamos antenoche nosotros tres (Miltín, 20). ${ }^{8}$

Tras esta observación, cuya función en la novela es apenas descriptiva, se esconde un mundo de referencias culturales. El francés incrustado y no traducido, en primer lugar, pero también la mención a una obra estrenada en alemán recién en 1928, y conocida por Emar en años inmediatamente posteriores, muy probablemente en París, nos hablan de una porosidad cultural bien sintonizada con la cosmópolis.

Pero el cosmopolitismo, como práctica cultural o tendencia epocal, no puede contraponerse directamente con el nacionalismo. En muchos escritores latinoamericanos ligados a la vanguardia existe una aguda preocupación nacional que, a veces, convive coordinadamente con los horizontes mundiales, y sólo en algunas ocasiones se vuelve rechazo y afirmación nacionalista estrecha. ${ }^{9}$ Emar, cosmopolita como el que más, interviene

\footnotetext{
${ }^{7}$ Landru fue un asesino, ladrón y seductor que se especializó en las viudas de los soldados de la Primera Guerra Mundial: las enamoraba y luego las mataba para quedarse con sus bienes. El juicio en su contra se ventiló entre en 1920 y 1921.

${ }^{8}$ Juan Emar. Miltín 1934. Santiago: Dolmen, 1997. Citaremos por esta edición, salvo indicación contraria.

${ }^{9}$ En José Carlos Mariátegui encontramos un buen ejemplo de la primera actitud: "No obstante esta impregnación de cosmopolitismo, no obstante su concepción ecuménica del arte, los mejores de estos poetas vanguardistas siguen siendo los más Argentinos. La argentinidad de Girondo, Güiraldes, Borges, etc., no es menos evidente que su cosmopolitismo” (1991:543).
} 
activamente desde sus Notas de Arte en el debate sobre el arte nacional de una forma que sorprende por la consistencia que mantiene con su pensamiento estético global.

El punto de partida es la separación entre una cierta "lógica" que debe plantear un nuevo problema y la práctica adocenada de lógicas preteridas. En sus Notas de Arte, Emar llama "tradición de la forma” a la repetición de lo ya conocido, y "tradición del espíritu” a la búsqueda permanente: "a la primera, la he llamado muerta; a la segunda, viva” ("Algo sobre pintura moderna. Ingres-Cézanne”, abril 20 de 1923:51). La crítica, a su juicio, tiende a confundir ambas instancias y llama nacional o patriótica a la repetición de fórmulas que ni siquiera son autóctonas en su origen sino importaciones tan antiguas ya que las consideramos propias. ${ }^{10}$ En Miltín 1934 se nos ofrece una sátira despiadada, con nombres y apellidos, de este criterio estrechamente nacionalista, que citaremos con alguna extensión por su claridad ${ }^{11}$

\section{CUENTO FRANCÉS}

(Dedicado a don Abel Valdés)

Ayer por la tarde pasé por l'avenue de l'Opera, crucé el boulevard des Capucines y al llegar al parc des Buttes Chaumont entré a1 café de la Paix donde tomé una fine Courvoisiére. Luego me dirigí por la rue de la Chausseé d'Antin hasta la place de la Bastille, donde me encontré con Monsieur de Bordeaux Poitiers que al verme me dijo: Au revoir!

Otro peruano, César Vallejo, critica el cosmopolitismo vanguardista (sin caer en el nacionalismo obtuso, eso sí) en su ensayo "Contra el secreto profesional. Acerca de Pablo Abril de Vivero”, allí intenta develar el origen europeo (y espurio, por lo tanto) de los aportes de la vanguardia hispanoamericana (nueva ortografía, nueva caligrafía, la máquina como asunto, metáforas imposibles, conciencia cósmica, comunismo integral), y termina abogando por "un timbre humano, un sabor vital y de subsuelo, que contiene, a la vez, la corteza indígena y el sustractum común a todos los hombres” (1991:554).

${ }^{10}$ Como lo dice el propio Emar en su coloquio final con Rubén de Loa, ironizando los lamentos de los defensores del arte nacional: "Nuestra originalidad se empaña bajo influencias ajenas, influencias del viejo mundo, del otro hemisferio... Fidias está inquieto, en la Chimba; Rembrandt tiembla, junto al Mapocho; Leonardo llora, en Baruri [sic]; Velásquez protesta en la Cañadilla; Ingres se desespera, en las Hornillas; Miguel Ángel está triste en la Avenida Matta, ¿Qué tendrá Miguel Ángel?” (Miltín, 188).

${ }^{11}$ Los tres personajes aludidos en las dedicatorias del fragmento son críticos literarios chilenos. Manuel Vega Santander (1899-1960), crítico del Diario Ilustrado, participó de la polémica entre criollistas e imaginistas a favor de los primeros. Abel Valdés Acuña (1906-1984) fue abogado, cronista literario y miembro de la Academia Chilena de la Lengua. Norberto Pinilla (1902-1946) fue un connotado estudioso de la literatura chilena, autor de una Biografía de Gabriela Mistral y de varios estudios sobre literatura del siglo XIX, entre otras obras. 
Ignacio Álvarez

\section{CUENTO INGLÉS}

(Dedicado a don Norberto Pinilla)

Ayer por la tarde pasé por Piccadilly Circus, crucé Regent Street y al llegar a Marble Arch entré al Tames Bar donde tomé a whisky and soda. Luego me dirigí por Hyde Park hasta White Chapel donde me encontré con Mister Birmingham, que al verme me dijo: Good bye!

\section{CUENTO ESPAÑOL}

(Dedicado a don Manuel Vega)

Ayer por la tarde pasé por la calle Alcalá, crucé la carrera de San Jerónimo y al llegar a la Castellana entré al café del Pombo, donde tomé un jerez de la Frontera. Luego me dirigí por la Gran Vía hasta la Puerta del Sol, donde me encontré con el señor de Toledo y Burgos que al verme me dijo: ¡Adiós! (138-9).

Los tres "cuentos patrióticos" de Miltín 1934 comparten un solo e idéntico procedimiento de composición y, en virtud de esa uniformidad, anulan la diferencia nacional que pretenden exaltar: es evidente que en ellos no hay nada que sea característico de Francia, Inglaterra o de España. En otro contexto —el del cine y la incipiente producción cinematográfica chilenaEmar agrega algunos datos a este argumento: si el cine nacional (y la novela nacional, inferimos) es una copia de las producciones extranjeras $-\mathrm{y}$ peor, una mala copia - aplaudirlo por el mero hecho de haber sido realizado en Chile es pura condescendencia e inercia. La única respuesta posible ante el nacionalismo irreflexivo de las artes locales es rechazar esas obras y la versión espuria de la nación que reproducen y promueven: "hay veces que es mejor ser antipatriota”, concluye ("Pantalla”, mayo 27 de 1925:175).

Cerrado ese camino ¿Cuál es, entonces, la posibilidad de un arte nacional? La solución comienza a vislumbrarse, paradójicamente, desde Europa. Santiago, que funciona para Emar como una sinécdoque de Chile, concentra los peores atributos. Es la periferia cultural y social, reino de la monotonía realista, del pensamiento único, de la planicie y del aburrimiento hasta en lo espacial: casas cuadradas, calles cuadradas, se queja. ${ }^{12}$ París, en cambio, no pertenece a Francia sino al mundo: es la cosmópolis, la ciudad

\footnotetext{
${ }^{12}$ En Miltín, Emar la llama “ciudad adormecida” y critica su trazado: “Las calles de mi ciudad son largas, largas. Mas como están todas colocadas paralelamente a distancias iguales y a distancias iguales también cortadas por otras tantas calles paralelas, las calles de mi ciudad son cuadradas” (50). Para una interpretación del plano de San Agustín de Tango — ciudad imaginaria de Ayer y de Umbral - en contraste con el damero hispánico que rechaza en este fragmento de Miltín, Cfr. Patricio Lizama. "El plano de San Agustín de Tango". Taller de Letras 36 (2005):121-133.
} 
internacional, sinécdoque ya no de un grupo de hombres sino de la humanidad como un todo. En términos culturales, París es la fuente de esa viva "tradición del espíritu” que tanto aprecia, el lugar donde está todo y, por lo tanto, el espacio que permite la mayor libertad y la mayor protección contra las influencias. ${ }^{13}$ Si ser artista chileno es, en primer lugar, ser un artista, el único lugar donde un hombre puede comenzar su recorrido es París.

Dado París - es decir, puestos en la búsqueda de una obra viva — Emar reintroduce lo nacional ya no desde la perspectiva de los objetos de la representación (el camino que ha demostrado inviable), sino desde "los procesos de producción de los aparatos estéticos”, como lo ha puesto Grínor Rojo en un contexto más general (2006:199). Proceso, no objeto: el cosmopolitismo de Emar implica la afirmación de lo local simplemente porque lo local se inscribe en el texto durante una escritura que actúa performativamente y se ancla por medio de la deixis, como señala en sus "Ideas sueltas sobre literatura” y en "Pilogramas"

Toda buena novela huele un color local, se localiza en el mundo; como todo ser viviente se localiza en alguna raza, especie familia. Huele así, porque el autor verdadero ha extraído sus materiales de la observación directa (“Ideas sueltas sobre litertura”, junio 18 de 1924:117).

Toda buena obra tiene sus raíces en la tierra, ha encontrado sus materiales en la tierra y en la vida ("Pilogramas", octubre 16 de 1924:139).

Por cierto, en estas definiciones se esconden algunas sutilezas de las que conviene tomar apunte. La representación no aparece envuelta en la metáfora visual corriente (el color local) sino referida a través del olfato, un sentido del cual no solemos ser conscientes sino cuando nos sorprende: hay, por lo tanto, un trabajo atento en la lectura que debe descubrir este "olor local”. En la escritura, a su vez, lo nacional no es algo dado a priori que se represente, sino algo que impregna el trabajo preciso y creativo de escribir. La nación, por lo tanto, deja de ser un proyecto abstracto que se construye o inventa juiciosamente siguiendo los dictados de la razón. Se ha vuelto "tierra”, una palabra que no sólo quiere decir naturaleza o suelo, sino que

\footnotetext{
${ }^{13}$ En palabras de Luis Vargas Rosas, entrevistado por Emar: "Yo creo que París es el sitio en que más libre puede estarse de influencias, pues hay allí tal exaltación de la personalidad, hay tantas corrientes, tal fiebre de investigación, que todo dogma, toda barrera que quiera anteponerse al desarrollo de cualquiera posibilidad, se derrumba" ("Luis Vargas Rosas”, junio 3 de 1923:71).
} 
Ignacio Álvarez

transmite en este contexto las referencias que tiene, por ejemplo, en una palabra como “desterrado” (referencias de raíz nutritiva, sustrato cultural).

\section{TÍTULO, LENGUA, CONTEXTO: AROMAS NACIONALES EN MILTÍN 1934}

La escritura de Miltín 1934 está motivada, primordialmente, por preocupaciones que escapan a lo nacional: el conocimiento superior, la actividad artística, el surgimiento del sujeto. No obstante ello, la reflexión teórica llevada a cabo por Emar en la década del veinte permite intentar una lectura interlineal de lo comunitario, que consiste en buscar e interpretar las huellas, los "aromas" nacionales que han quedado impresos en la novela durante su elaboración. Es lo que haremos a continuación, intentando respetar la preferencia analítica de Emar por la producción antes que por la representación. Leeremos, en primer lugar, el modo en que lo nacional queda representado en el título de la novela (categoría pragmática y representativa, al mismo tiempo, del proceso productivo y de su objeto), ${ }^{14}$ en la lengua de su escritura y, finalmente, en las observaciones - a menudo críticas- sobre el contexto chileno que siembra a lo largo del relato.

¿Por qué, entonces, Miltín 1934? Sabemos por qué “1934” — porque la novela constituye una suerte de diario de vida, porque es escritura deíctica que debe ser terminada con las últimas horas de ese año así como el "Cuento de la medianoche” debe ser escrito justo a la medianoche-- ${ }^{15}$ pero ignoramos

\footnotetext{
${ }^{14}$ Como ha estudiado Gérard Genette (2001) el título en tanto paratexto constituye —no por casualidad el término es emariano - un umbral: "zona indecisa” entre el adentro y el afuera, sin un límite riguroso ni hacia el interior (el texto) ni hacia el exterior (el discurso del mundo sobre el texto) (7-8). Cumple una función pragmática, por una parte, porque "es aquello por lo cual un texto se hace libro y se propone como tal a sus lectores, y más generalmente, al público” (7). Su representatividad - muy problemática en términos teóricos - se produce porque cumple tres funciones: designar (dar un nombre), tematizar (mostrar de qué trata el libro) y "rematizar" (indicar qué es el libro en cuanto obra) (68-80). El título de Miltín 1934 las conjuga de modo patente: mencionando a Miltín-personaje en el título (aspecto temático), señala una clave de lectura, un género: como veremos, esa clave de lectura está estrechamente ligada al relato de la historia de Chile. En último término, Miltín 1934 es la clase de títulos que Adorno consideraba como los mejores: "Los buenos títulos están tan próximos al asunto que respetan su ocultamiento" (2003:315).

${ }^{15}$ El relato acaba de modo más o menos abrupto cuando Emar escucha el estampido de un cañón que anuncia el nuevo año, lo que caduca el relato (Miltín, 224). Al respecto, vale la pena mencionar que el fragmento "Frente a los objetos", publicado en la revista Todo el mundo en síntesis, fue presentado por su autor en diciembre de 1935 como un adelanto de la novela “Miltín 1935, por aparecer”, y no está incluido en Miltín 1934, que había sido publicada en junio de ese mismo año (Lizama 1988:137). Que en esos momentos pensara seguir datando su producción es, a mi juicio, un índice claro de su afán deíctico.
} 
todavía por qué “Miltín”. El nombre pertenece a un cerro de la actual provincia de San Antonio, y está ubicado de manera bastante precisa en el mapa que Gabriela Rivadeneira dibujó para la primera edición del libro (1935:75). A partir de ese dato real, Emar fabula la existencia de Miltín, un antiguo cacique que habría comandado, en 1541, una singular defensa araucana contra una no menos singular ofensiva española. A un Pedro de Valdivia armado con ametralladoras, morteros, aviones y hasta apoyado por el Regimiento General Baquedano $N^{\circ} 7$, el cacique responde con disciplinadas formaciones de indios que atacan con gases asfixiantes y cientos de machis que soplan gases hilarantes. Miltín es derrotado, llora por días sin que nadie conozca la causa y luego se suicida. ¿Cuál es la razón de sus lamentos? La conjetura más extendida — según Emar- es que Miltín habría visto el futuro aciago de los españoles-chilenos y que deplora sus desgracias: "desde aquel momento, se comprenderá, no hubo en Chile calamidad, accidente o desastre que todo buen católico no creyera ser lo antevisto por Miltín” (76).

El vínculo entre este episodio y el título de la novela es significativo, pues entrega una pauta de lectura global. "Hoy [señala Emar, y eso significa el largo día, la larga noche, el breve año de su escritura] he subido al cerro Miltín y desde allí he visto todo cuanto aparece en este libro y cuanto en él aparecerá y pueda aparecer" (77). Si lo que se ve desde ese cerro es la historia de Chile (al menos esa es la conjetura más extendida), entonces no resulta completamente descabellado conjeturar que el libro en su conjunto, y no sólo la aventura del cacique, constituye a su desenfrenada manera una versión posible de la historia patria que debe ser recuperada por la lectura. Naturalmente, entonces, surge la pregunta por aquello que caracteriza a la novela y que, al mismo tiempo, constituye el rasgo distintivo de la historia de Chile que ofrece Emar.

Ambos relatos, el de Miltín y el de la novela, comparten lo que podemos llamar una concepción sincrónica de la narración, que consiste en la sistemática -y paradójica- derogación del transcurso temporal como articulador del relato histórico y del relato literario. Su matriz aparece desarrollada de forma explícita en el episodio del cacique Miltín, el único pretendidamente histórico de la novela. Si las machis producen gases lacrimógenos, si los aviones y los regimientos de la más que centenaria república colaboran con el conquistador Pedro de Valdivia, entonces los personajes, los objetos y - en último término- los períodos de la historia se han condensado en un único instante, en el aquí y ahora de la batalla que, también, es el aquí y ahora de la escritura. Emar, en otras palabras, no piensa el relato —nacional o literario- en términos cronológicos lineales sino de una manera estrictamente sincrónica; para evocar el pasado, por ende, debe 
Ignacio Álvarez

construir un presente que lo pueda contener, pues el presente es la única temporalidad del acto de escribir que, a su vez, constituye el acto de existir.

Esta concepción sincrónica de la historia y del relato aparece, también, en otros lugares de la novela y su recurrencia nos permite decodificar el valor ideológico que posee como procedimiento. En su debate con los críticos literarios chilenos, por ejemplo, Emar los encuentra culpables de lo que llama "miedo negro de equivocarse" (42), que es el temor a que la posteridad no confirme el día de mañana sus juicios sobre las obras de hoy. El argumento que utiliza para contradecirlos es una nueva derogación de la temporalidad como transcurso aunque, esta vez, lo que intenta derribar no es el pasado sino la posibilidad del futuro. La fórmula para evitar el miedo al error consiste en desconfiar de las supuestas certezas que los hombres del mañana tendrán sobre lo presente: “¿Por qué dar tanta importancia a los señores del año 2000 y siguientes?” —recomienda— “ ¿Y si resultan una sarta de cretinos? (42). El futuro es una posibilidad abierta pero inaccesible para los ojos actuales, y por lo tanto debe suprimirse como una perspectiva válida en el actuar presente.

Para poder pensar ideológicamente la sincronía, no debemos olvidar que historia y controversia literaria, a su vez, están claramente enmarcadas en un contexto nacional: la historia intervenida es la de Chile, las opiniones pertenecen a críticos chilenos y se refieren a obras chilenas, los resultados de la acción cultural deben ocurrir en el campo literario chileno. ${ }^{16}$ De ello se sigue sin mucha dificultad que Emar entiende el espectro de lo nacional como algo reducido a lo puramente presente, y ello por una razón no del todo insospechada en su proyecto artístico. Enfatizar el ahora le permite eludir las prescripciones pedagógicas que tanto desde el pasado (la tradición), como eventualmente desde el futuro (la utopía o el temor a la utopía), presionan y limitan la libertad de un individuo que se quiere definir como nacional. Dicho de otro modo: Miltín (el cacique, la obra y su historia de Chile) busca derogar las ataduras del pacto decimonónico, cuyas rémoras aún persisten dolorosamente, para abrir un espacio ideológico que potencialmente permitiría la construcción contingente de un nuevo sujeto nacional. ${ }^{17}$

\footnotetext{
${ }^{16}$ Vale la pena apuntar que la inscripción nacional de este procedimiento no es exclusiva, pues la identidad tampoco se inscribe únicamente en el rango nacional. Emar habla, en todo momento, en términos universales y nacionales al mismo tiempo. No sólo se refiere a la historia de Chile, ni tampoco exclusivamente al arte chileno. Para la simultaneidad de los niveles de identidad (Cfr. Rojo 2006:22-38).

${ }^{17}$ Homi K. Bhabha distingue en la nación dos de las temporalidades que aludimos aquí: el pasado y el presente. "En la producción de la nación como narración”, señala, "hay una escisión entre la temporalidad continuista, acumulativa de lo pedagógico [nuestra "tradición” o "historia”] y la estrategia repetitiva, recursiva, de lo performativo [el lugar de la construcción
} 
Una segunda huella - evidente y sin embargo difícil de interpretartiene que ver con el lenguaje de Miltín, con el uso consciente y gozoso de algunas variedades sintácticas y léxicas típicas del español de Chile, así como con cierta manía geográfica al momento de bautizar a sus personajes. No es inocente, a mi juicio, que exista un capitán Angol, un Rubén de Loa, un doctor Hualañé, un Martín Quilpué, o que parte importante de la acción transcurra en Illaquipel, cuna de los perenquenques, ni menos que a mitad de una discusión (la de la crítica literaria) Emar se dé tiempo para una espontánea digresión filológica: "No sé qué... qué... (la palabra "intuición" ya no se puede emplear) qué... qué... ¡tinca! (iqué hermosa palabra! ¿Por qué no darle carta de ciudadanía?) no sé qué tinca me hace asegurar que el autor se ha colocado ante las letras chilenas del siglo XX como crítico y, como tal, nada más que como tal, ha escrito” (39).

Mirados de cerca, el uso de la geografía como onomástica y del dialecto como lengua literaria apuntan en direcciones diferentes. En efecto, la identificación de los personajes con ciertos lugares de Chile (normalmente pueblos, ciudades o accidentes excéntricos en relación con Santiago) pone en marcha un complicado mecanismo alusivo y relativamente humorístico que implica, al menos, tres pasos para su funcionamiento cabal: reconocer al sujeto nombrado como personaje, reconocer su nombre como mención geográfica y mantener ambas significaciones actualizadas durante la lectura. Constituye un guiño criollo, un chiste permanente y en sordina que sólo entrega su cuota de placer a quienes conocen la nomenclatura geográfica de Chile, es decir, a los chilenos (puesto en otros términos, busca un solo lector, de entre todos los lectores posibles, para darse en su placer: el lector chileno). La estrategia del sobrentendido, en consecuencia, produce una fusión entre el mundo interior de la novela y el exterior de los lectores, una fusión análoga pero distinta de la que, en el siglo XIX, producían los primeros textos latinoamericanos que afirmaban lo nacional como imaginario. Es una fusión análoga en tanto el lector de Miltín y el lector de Martín Rivas pueden decir que entienden de lo que se habla, pues se habla precisamente de ellos, de sus lugares y de sus costumbres, ${ }^{18}$ a diferencia de los textos decimonónicos, en los cuales la nación se lee como un proyecto inequívocamente afirmativo, el suave “chiste nacional” de Miltín mantiene una ambigüedad que es propia del

contingente del sujeto nacional]” (2002:182). Como es obvio, además, la performatividad de la escritura de Emar entronca claramente con la performatividad del relato nacional: si el sujeto se construye mediante un acto de habla ilocucionario, la nación aparece como perlocución.

${ }^{18}$ La fusión del mundo novelesco y el mundo exterior en novelas como Noli me tangere de José Rizal y El Periquillo Sarniento de José Joaquín Fernández de Lizardi es descrita por Anderson (53-4). 
Ignacio Álvarez

ambiente crítico del que emerge: constituye comunidad entre quienes comprenden la alusión, pero relativiza su valor por el matiz humorístico que acompaña al reconocimiento y que socava cualquier intento de mistificación. Como resume el propio Emar: "todo el mundo en Chile es chileno. Es algo desesperante" (1997:34).

En el registro lingüístico de Miltín 1934, por su parte, alienta un claro afán por derribar el muro secular que hasta entonces, en Chile y en el resto de Latinoamérica, había separado la lengua "pública y de aparato", primordialmente escrita, de la lengua "popular y cotidiana”, básicamente oral (Rama, 2004:73-4). ${ }^{19}$ Aun cuando el naturalismo literario — señala ahora Jorge Schwartz- se interesó por el pueblo bajo, mantuvo sin embargo la distinción por medio de una virtual "esquizofrenia" al interior del relato, reservando para el narrador el lenguaje letrado y para las intervenciones de la plebe el habla popular (1991:84). ${ }^{20}$ En esa circunstancia la situación de Miltín 1934, aunque rupturista, es problemática. Así lo muestra el siguiente ejemplo

¿Y si durante el siglo XXIII los hombres agobiados de ciencias y certezas, de vida en tubos de hierro y bajo sonidos estridentes, cambiando el cerebro por los alimentos químicos, la sensibilidad por las bebidas eléctricas, no deseen, no pidan, no imploren más que un eco dulce, dulzón, azucarado, latigudo, pegajoso, mieloso, turronoso, manjarblancoso de aquellos buenos tiempos, de aquel paraíso perdido de hace tres siglos, cuando se discutía aún sobre arte, cuando se caminaba acechado por los habitantes del astral, cuando se comían guatitas a la chilena y se bebía pisco legítimo de pura uva? (43)

Ante todo, debemos retener que aquello sobre lo que se discute es un tópico eminentemente letrado, esto es, el valor estético en literatura. Sin embargo, es evidente que el tratamiento lingüístico que recibe ese tópico

\footnotetext{
${ }^{19}$ Á. Rama, de quien tomo esta distinción, enfatiza el carácter diglósico de los latinoamericanos desde la Colonia: en la vida privada y en las relaciones con la plebe se utiliza "la algarabía, la informalidad, la torpeza y la invención incesante del habla popular”; en la escritura se usa un habla mucho más rígida, y en sus inicios "fuertemente impregnada por la norma cortesana proveniente de la península” (2004:73-4).

${ }^{20}$ Un buen índice del carácter ideológico de esa separación, mejor quizá que un fragmento ilustrativo de sus obras, nos lo ofrece Mariano Latorre en su “Autobiografía de una vocación”. Allí evoca la identificación de su propia curiosidad por el habla chilena —es decir, por el habla de la plebe - con la de Rodolfo Lenz, su maestro alemán: "Reparé, sí, al lado de Lenz, en cierta cualidad sicológica que me inclinaba a ver en los mestizos y en su paisaje cierta novedad que era la misma adivinada por Lenz, desde el punto de vista filológico” (1971:32). Latorre se piensa letrado, narrador y extranjero como Lenz: observa con curiosidad, entonces, el habla que imitará en la pura instancia del discurso directo cuando escriba sus novelas.
} 
abarca el uso de registros hasta ahora inéditos en boca de un narrador novelesco, y que - en el ámbito específico de lo gastronómico en este casovan de lo íntimo (mieloso, turronoso, manjarblancoso) a ciertos aires populares (guatitas a la chilena).

A diferencia de otras rupturas lingüísticas asociadas a la vanguardia, como el neocriollo del argentino Xul Solar o la ortografía indoamericana del peruano Fransisqo Chuqiwanka (Schwartz 1991:61-78), la escritura de Miltín 1934 no tiene un carácter nacionalista o regionalista, aunque posee, por cierto, un inequívoco aroma nacional que es claro para cualquier hablante del español de Chile. Se trata de un aroma reconocible que abre la diglosia latinoamericana descrita por Ángel Rama en una poliglosia chilena organizada alrededor de los ejes público/íntimo y letrado/popular, una poliglosia que nos habla certeramente de Emar y de su situación en el imaginario nacional. Las operaciones lingüísticas de Miltín 1934, en efecto, quedan mejor descritas si pensamos que su escritura no puede (o mejor: no quiere o no se interesa) en atravesar el eje que separa al hombre letrado de la plebe, como sí puede (y quiere y se interesa) en dar espacio a una expresión lingüística íntima en un contexto público como es la novela. Dicho de otro modo, la escritura de Emar es paradójica si se la lee buscando una imagen de la nación: parece progresista y conservadora al mismo tiempo. Mantiene unas coordenadas de referencia que pertenecen al orden nacional, es cierto, pero las interviene para introducir la posibilidad de un individuo que, sin negar su vinculación comunitaria, escape de las coacciones y limitaciones que esas mismas coordenadas generaron y obligaron en el pasado. Esa ruptura, sin embargo, ocurre sólo en el orden individual y en una perspectiva meramente horizontal, pues soslaya, o tal vez no percibe, un eje de conflictos que será fundamental a lo largo del siglo XX: el eje de las clases sociales.

Miltín 1934, por último, contiene numerosas observaciones críticas acerca del contexto chileno, cuya filiación ideológica es difícil de precisar. Hay, en primer lugar, signos evidentes que constatan la "crisis moral" de la oligarquía y su incapacidad para solucionar los problemas acuciantes del inicio del siglo; en esa clave puede leerse la historia del pato de Clarisa, que fue salvado de las fauces de un perro, elegido Senador y Presidente de la República y luego escabechado por "finos gastrónomos" (55-56). Hay también cierta conciencia - pero es una conciencia lateral y episódica- de las brutales desigualdades que deja el balance entre ricos y pobres, como lo muestra el irónico juego verbal entablado a propósito de la escritura del libro "La buena mesa" y un hipotético "Buen ropero", textos que solucionarían los problemas de comida y vestimenta que afectan a gran parte de la población gracias al buen gusto de los ciudadanos (144-145). 


\section{Ignacio Álvarez}

Hay también rasgos críticos, pero, esta vez acusados y explícitos, contra el moralismo obtuso y la consecuente monotonía nocturna de la sociedad santiaguina, como lo muestra la rabia apenas contenida de Emar contra los finos comensales que se asoman por el cabaret Arno sólo para mirar y demonizar a los viciosos y lascivos que acuden allí a divertirse de verdad (25-28). Hay, por último, cierta suspicacia ante el proyecto de desarrollo industrializante y populista de la dictadura de Ibáñez, representado por el quinto sabio de Illaquipel, incapaz de lograr que los perenquenques agiganten, como lo hacen con las fucsias, las semillas comestibles, el ganado o los repuestos que requieren las máquinas que nos llevarán a las puertas del progreso (121123). ${ }^{21}$

En conjunto, estas observaciones delinean aproximadamente lo que Bernardo Subercaseaux llama "categoría espiritual" de lo antiburgués (2004:76-78), y que Nelson Osorio describe acertadamente como cierta "comunidad en la actitud cuestionadora" que, sin embargo, no encuentra "coincidencia en las respuestas, que son variadas, multifacéticas y hasta contradictorias” (1988:XXIX). ${ }^{22}$ Digo “aproximadamente” porque los gestos de rechazo que se leen en Emar — rechazo a la oligarquía, a las desigualdades económicas, a la moralina burguesa y al populismo ibañista- no están acompañados por una propuesta utópica que los complemente, como sí ocurre en la obra de muchos de sus contemporáneos. Si concordamos con la historiografía chilena en que el fenómeno más trascendente del siglo XX es la admisión de las clases populares a la vida política, si reconocemos luego que la fuente utópica del siglo proviene justamente de ellas, entonces el espíritu antiburgués de Emar queda relativizado o inmovilizado por una voluntad igualmente fuerte hacia la individuación que rechaza un colectivismo, por otra parte, ya maduro en la década del treinta. Ello explica que las masas populares se nos muestren sólo contadas veces en Miltín 1934, y siempre matizadas con un cierto aire derogatorio. El mejor ejemplo de ello lo encontramos en las voces que interrumpen el sueño visionario del narrador

duermo, duermo. Cosa curiosísima: no he soñado nada. Sólo antes de despertar, creo, entre sueños, que el mundo se viene abajo. Chocan soles

${ }^{21}$ Este episodio está datado con irónica precisión: el sabio $5^{\circ}$ recibe órdenes del supremo gobierno en 1927 y 1928, años en que Ibáñez ejercía el poder estatal sin contrapesos.

${ }^{22}$ Un ejemplo visible de actitud antiburguesa y respuesta idiosincrática es el caso de Vicente Huidobro, doctrinalmente impecable en su "Balance patriótico" (2003) y políticamente miope en su candidatura presidencial de 1925. Sobre lo antiburgués como "categoría espiritual”, Cfr. Subercaseaux (2004:76-78). Para una lúcida mirada a este mismo problema en el caso de las vanguardias europeas, Cfr. R. Williams (2002:71-87). 
y planetas. Pero no. Es una turba que pasa por la calle vociferando. Sus gritos me han arrancado del sueño: “iViva Grove!” (53-54).

A partir de este fragmento sería posible deducir toda la problemática ideológica de Emar: el narrador duerme y, casi en contacto con la vigilia, alcanza a soñar (esa actividad individual por antonomasia, ese delirio repugnante al burgués) con el rango de las categorías universales. Su sueño, sin embargo, se ve interrumpido por un pueblo que, en la escritura de Miltín 1934, es sólo esa molesta "turba" que aclama al presidente de una efímera e ilusoria República Socialista.

El espacio que marcan los aromas nacionales de Miltín 1934, en suma, puede describirse en tres instancias contradictorias. Historia nacional, sí, pero historia inmediata del aquí y del ahora que permite la construcción contingente del sujeto. Palabras nacionales, sí, pero dichas desde una ironía que desmitifica la nación, palabras nacionales que buscan la expresión individual y soslayan el eje mayor que constituye la diferencia de clase. Espíritu antiburgués, sí, pero también un rechazo al movimiento popular que arrastra las masas hasta el marco de la propia ventana.

\section{LA ENCRUCIJADA DEL SUJETO}

¿Cómo se representa la nación chilena en esta novela, al fin y al cabo? Nuestra respuesta es relativamente sencilla: como una comunidad en tiempo presente que ya no puede recurrir a su historia sin anquilosarse; como una comunidad que arrastra todavía algunos rasgos del pacto recién caduco, es decir, intelectualmente estrecha y moralmente asfixiante; como una comunidad dividida entre su ociosa y conservadora burguesía y una multitud inorgánica y vociferante.

En Miltín 1934, sin embargo, la experiencia nacional es problematizada por la situación dividida del narrador emariano. El recurso a la historia patria y al lenguaje nacional está en el corazón de Chile, tal vez en forma combativa, pero afirmándolo como existente en su propia oposición. El rechazo al pasado como tradición y al futuro como utopía, la palabra irónica que relativiza el vínculo comunitario, la palabra íntima que comunica más y mejor que el habla socializada, el rechazo a la multitud y, en fin, todos los rasgos que recusan el contacto con el otro, eclipsan - a su vez- los brillos de lo nacional. Cercanía a la comunidad por un lado, distancia de ella por el otro.

Cercanía y lejanía, sin embargo, son polos más complejos de lo que parece, pues es posible reinscribirlos en la tríada dialéctica de lo individual, lo 


\section{Ignacio Álvarez}

particular y lo universal. ${ }^{23}$ La visión de la totalidad —el proyecto artístico central de Emar - y el cosmopolitismo — su afirmación teórica - constituyen asíntotas hacia la categoría de lo universal, del mismo modo que la soledad del creador de Umbral, la búsqueda de una expresión auténtica y el surgimiento del individuo en la contingencia del presente lo son de lo individual. Lo particular que, como señala Lukács, constituye "la expresión lógica de las categorías sociales” (1960:102), ${ }^{24}$ se corresponde en nuestro análisis con el problemático dominio de lo nacional en la novela.

Desde esa perspectiva, Miltín 1934 construye un sujeto que debe enfrentar con dolor la inestable coyuntura que le plantean estas tres categorías en un momento singular de la historia de Chile. Se trata de un momento en el cual — desde la posición de Emar - se vive el agotamiento ya definitivo del proyecto nacional decimonónico, pero no se avizoran todavía interlocutores que puedan dialogar con la apertura radical de su propuesta estética y las implicancias que ella tiene en el terreno ideológico. Aunque es innegable que la penetración teórica de Emar barrunta una posible dialéctica entre lo universal, lo individual y lo particular —no por nada se preocupa largamente por la cuestión de la representación de la nación- los términos de la tríada se nos muestran bajo la forma de opciones excluyentes, de caminos que se apartan. El relato, en efecto, vive angustiosamente la encrucijada de un sujeto que se ha liberado de las cadenas del nacionalismo decimonónico y tiene ante sí dos posibilidades: integrar un nuevo pacto, intuido pero en el fondo desconocido desde la atalaya emariana, o intentar mantenerse al margen de toda determinación comunitaria.

Los escasos momentos de plenitud o trascendencia que el Emar de Miltín 1934 logra vivir y escribir, es claro, se encuentran en el rápido fluir de lo individual a lo universal, en la posibilidad de encontrar la sabiduría total en el individuo aislado. En Miltín 1934, a mi juicio, Emar resuelve su encrucijada mediante el aislamiento y negando, consecuentemente, un vínculo que supone asfixiante, o bien a través de una espiritualización universa-lizadora de ese vínculo que lo diluye hasta hacerlo imposible en la práctica ${ }^{25}$

\footnotetext{
${ }^{23}$ Hegel observa que lo individual se constituye por la reflexión del concepto en sí mismo, lo universal como el "alma muda" de lo concreto que existe en sí, y lo particular como diferencia o relación de lo uno con lo otro (1968:547;533;536).

${ }^{24}$ Grínor Rojo es quien expone la dialéctica universal-individual-particular en términos de la identidad. Este análisis sigue de cerca sus proposiciones, sobre todo, en el recurso a Hegel y Lukács (2006:22-38).

${ }^{25}$ Ernst Tugendhat, sagazmente, apunta que "la relación moral que debemos tener hacia todos los hombres (es decir, en el plano universal) se difundiría en una abstracción si no nos tuviéramos que relacionar éticamente con nuestra nación” (1996:37-8). Cuando Emar, como en
} 
No podemos salirnos de nosotros mismos y... estamos obligados a mirar el mundo a través de nosotros. El Yo siempre estará allí como una prisión. Sí. Mas como el Yo es infinito, es como si pudiésemos mirar el mundo desde cualquier sitio y bajo cualquier personalidad (29)

En último término, la actitud de Emar significa una renuncia ética a la comunidad nacional $\mathrm{y}$, al mismo tiempo, una renuncia política a la horizontalidad interclasista que propondrá el diseño de la nación durante el siglo XX. Abiertamente modernizador en el terreno estético, es difícil concederle a Emar, entonces, un lugar de vanguardia en lo social.

En esta relativa incapacidad de reconocerse como sujeto renovadamente nacional, en la imposibilidad de comunicar lo universal e individual con lo particular y comunitario, late no obstante la mayor necesidad de este nuevo pacto nacional en ciernes: la existencia de mediadores o traductores entre los diversos estamentos de la sociedad.

\author{
Universidad Alberto Hurtado* \\ Departamento de Lengua y Literatura \\ Facultad de Filosofía y Humanidades \\ Alameda Bernardo O’Higgins 1869, Santiago (Chile) \\ ialvarez@uahurtado.cl
}

\title{
BIBLIOGRAFÍA
}

ADORNO, Theodor W. "Títulos”, en Notas sobre literatura. (Trad. Alfredo Brotons Muñoz). Madrid: Akal, 2003.

ANDERSON, Benedict. Comunidades imaginadas. (Trad. Eduardo Suárez). México: F. C. E., 2000.

BHABHA, Homi K. "DisemiNación. El tiempo, el relato y los márgenes de la nación moderna”, en El lugar de la cultura. (Trad. César Aira). Buenos Aires: Manantial, 2002.

EMAR, Jean. Notas de Arte (Juan Emar en La Nación: 1923-1927). Estudio y recopilación de Patricio Lizama. Santiago: RIL/Centro Investigaciones Diego Barros Arana, 2003.

EMAR, Juan. Miltín 1934. Santiago: Dolmen, 1997.

------ Miltín 1934. Santiago: Zig Zag, 1935.

------- Umbral. Tercer Pilar: San Agustín de Tango. Santiago: DIBAM, 1996.

el ejemplo que sigue, busca la unión con el resto de los hombres a través de la contemplación interior, está incurriendo en la difusión de la que habla Tugendhat. 
Ignacio Álvarez

GAZMURI, Cristián (ed.). El Chile del Centenario. Los ensayistas de la crisis. Santiago: Pontificia Universidad Católica, 2001.

GELLNER, Ernest. Naciones y nacionalismo. (Trad. Javier Setó). Madrid: Alianza, 1991.

GENETTE, Gérard. Umbrales. México: Siglo XXI, 2001.

HEGEL, G. W. F. Ciencia de la lógica. (Trad. Augusta y Rodolfo Mondolfo). Buenos Aires: Solar-Hachette, 1968.

HOBSBAWM, Eric. "Etnicidad y nacionalismo en Europa hoy", en La invención de la nación. Lecturas de Herder a Homi Bhabha. Álvaro Fernández Bravo (ed. y trad.). Buenos Aires: Manantial, 2000.

------- Naciones y nacionalismo desde 1780. (Trad. Jordi Beltrán). Barcelona: Crítica, 1990.

HUIDOBRO, Vicente. "Balance patriótico", en Góngora, Mario. Ensayo histórico sobre la noción de estado en Chile en los siglos XIX y XX. Santiago: Universitaria, 2003.

HUNEEUS, Cristián. "Situación de Umbral”, en Artículos de prensa (19691985). Daniela Huneeus y Manuel Vicuña (eds.). Santiago: DIBAMLOM, 2001.

LATORRE, Mariano. “Autobiografía de un vocación”, en Memorias y otras confidencias. Santiago: Andrés Bello, 1971.

LIZAMA, Patricio. "Frente a los objetos: fragmento de Juan Emar”. Taller de Letras 26 (1988):137-41.

LUKÁCS, Georg. Literatura y arte como sobrestructura. Aportaciones a la historia de la estética. (Trad. Manuel Sacristán). México: Grijalbo, 1966.

MARIÁTEGUI, José Carlos. "Nacionalismo y vanguardismo en la literatura y en el arte”, en Schwartz, Jorge. Las vanguardias latinoamericanas. Textos programáticos y críticos. México: F. C. E., 1991.

OSORIO, Nelson. "Prólogo", en Manifiestos, proclamas y polémicas de la vanguardia literaria hispanoamericana. (Ed. Nelson Osorio). Caracas: Biblioteca Ayacucho, 1988.

PEÑA, Paula. "Diez cuentos como tubos de ensayo: del diálogo con la ciencia al diálogo con la cultura moderna en Diez de Juan Emar”. Tesis para optar al grado de Licenciada en Lengua y Literatura. Santiago: Universidad Alberto Hurtado, 2008.

PIÑA, Carlos; BRODSKY, Pablo; LIZAMA, Patricio. "Ausencia presencia de Juan Emar”, en Revista Universitaria 31 (1990):6-12.

RAMA, Ángel. La ciudad letrada. Santiago: Tajamar, 2004.

ROJO, Grínor. Globalización e identidades nacionales y postnacionales... ¿De qué estamos hablando? Santiago: LOM, 2006. 
ROJO, Grínor; SALOMONE, Alicia; ZAPATA, Claudia. Postcolonialidad y nación. Santiago: LOM, 2003.

SALAZAR, Gabriel; PINTO, Julio. Historia contemporánea de Chile, tomo I. Santiago: LOM, 1999.

SCHWARTZ, Jorge. “Introducción”. Las vanguardias latinoamericanas. Textos programáticos y críticos. México: F.C. E., 1991.

------ Vanguardia y cosmopolitismo en la década del veinte. Oliverio Girondo y Oswald de Andrade. Rosario: Beatriz Viterbo, 1983.

SUBERCASEAUX, Bernardo. Historia de las ideas y de la cultura en Chile. Tomo III. El Centenario y las Vanguardias. Santiago: Universitaria, 2004.

TUGENDHAT, Ernesto. "Identidad: personal, nacional y universal”, en Persona y sociedad 10 (Abril 1996):29-40.

VALENTE, Ignacio. “Juan Emar: Miltín 1934”, en El Mercurio (20 agosto 1972):7.

VALLEJO, César. "Contra el secreto profesional. Acerca de Pablo Abril de Vivero", en Schwartz, Jorge. Las vanguardias latinoamericanas. Textos programáticos y críticos. México: F. C. E., 1991.

WILLLIAMS, Raymond. La política del modernismo. Ed. Tony Pinkney. (Trad. Horacio Pons). Buenos Aires: Manantial (2002):71-87. 